УДК 347.133

DOI 10.33184/pravgos-2021.1.13

\title{
ПОВАРОВ Юрий Сергеевич
}

кандидат юридических наук, дочент, дочент кафедры гражданского и предпринимательского права Самарского национального исследовательского университета им. академика С.П. Королёва,

2. Самара, Россия.

E-mail:sl-su@mail.ru.

Cmaтьи в БД «Scopus»/«Web of Science»:

DOI: 10.17150/2500-4255.2019.13(5).846-855;

10.1007/978-3-030-29586-8_67; 10.1007/978-3-030-13397-9_54;

10.1007/978-3-319-75383-6_29

\section{РАЗГРАНИЧЕНИЕ СДЕЛОК \\ НА ТРЕБУЮЩИЕ И НЕ ТРЕБУЮЩИЕ ВОСПРИЯТИЯ: ОСНОВАНИЯ И ЗНАЧЕНИЕ}

Предложенная в науке классификация сделок на требующие и не требующие восприятия не получила системного отражения в российском гражданском законодательстве, более того, научный потенциал данной классификации нередко подвергается сомнению. Цели: раскрыть суть и значение деления сделок на требующие и не требующие восприятия; проанализировать подходы к определению критерия подобного разграничения; разработать механизм установления принадлежности той или иной сделки к определенной классификационной группе; исследовать вопрос о допустимости экстраполяции деления на иные (нежели односторонние сделки) юридические акты. Методы: общетеоретические - формальной и диалектической логики; частнонаучные - юридико-догматический, правового моделирования, сравнительно-правовой, толкования правовых норм. Результаты: доказываются ущербность игнорирования фактора (не)обязательности восприятия волеизъявления и, как следствие, значимость исследуемой градации (при том что отнесение сделки к разряду требующих или не требующих восприятия влияет на условия и момент наступления юридических эффектов ее совершения, а интерпретация сделки как рецептивной опосредует необходимость установления и соблюдения правил по поводу процедуры и адресата извещения о волеизъявлении); выделяются основные модели отражения юридической роли восприятия в приложении к сделкам, нуждающимся в восприятии; позитивно оценивается подход к 
идентификации сделки как (не)рецептивной исходя из прямых указаний закона и существа сделки; проводится мысль о целесообразности адаптации рассматриваемой классификации к юридическим актам, не являющимся односторонними сделками.

Ключевые слова: сделка; волеизъявление; совершение сделки; восприятие сделки; юридическая сила; доставка сообщения; адресат сообщения.

Дифференциация гражданско-правовых сделок на действия, требующие и не требующие восприятия (или, если угодно, на нуждающиеся и не нуждающиеся в приеме [1, с. 679]) лицом, к которому обращены сделочные юридические последствия, уходящая своими корнями в римское частное право (оговаривавшее для некоторых односторонних сделок атрибут рецептивности [2, с. 129]) и получившая активное распространение в германской цивилистике (при этом в специальной литературе обычно отмечается, что первенство в выведении стройной терминологии для изучаемой классификации принадлежит Э. Цительману [1, с. 679; 3, с. 57; 4, c. $103 ; 5$, с. 66]), до сих пор не нашла эксплицитного и комплексного отражения в отечественном гражданском законодательстве и доктрине. Между тем данная рубрикация имеет, как представляется, достаточно серьезное теоретическое и прикладное значение (в любом случае анализ факта надлежащего информирования определенных лиц, не участвующих в совершении сделки, довольно часто оказывается крайне существенным в срезе надлежащей оценки (не)наступления соответствующих правовых эффектов).

Симптоматично, что многие авторы находят уместным использование рассматриваемого разделения сделок при раскрытии самых разных правовых ситуаций и конструкций. Так, С.Ю. Болонин использует понятие сделки, требующей восприятия, при исследовании отношений по поводу согласования уступки требования, когда «для возникновения последствий необходимо, чтобы волеизъявление должника (согласие) было воспринято хотя бы одной из сторон сделки уступки» [6, с. 114]. На взгляд В.В. Ванина, извещение о проведении торгов представляет собой одностороннюю сделку, «порождающую правовые последствия лишь при условии восприятия опосредуемого ею волеизъявления адресатами» [7, с. 61]. А.В. Егоров фиксирует, что заявление о выборе в альтернативном обязательстве (самого предоставления, места и времени его осуществления) есть «односторонняя сделка, требующая восприятия» [8, с. 260]. М.А. Егорова использует понятие сделки, требующей восприятия, для выявления природы одностороннего отказа от исполнения договора [3, 
с. 57]. В качестве сделки, требующей восприятия, идентифицирует односторонний отказ от представительства Е.Л. Невзгодина [9, с. 29-30].

Вообще, для приверженцев обсуждаемого деления «шаблонной» является констатация того, что подавляющее большинство сделок нуждаются в восприятии (что, конечно, справедливо); в качестве же разновидностей действий, не требующих вручения, обычно приводятся завещание (это «образцовый» в плане рельефности выражения сути группировки пример), публичное обещание награды, акт учреждения юридического лица, отказ от права собственности $[4$, с. $103 ; 10$, с. $377 ; 11$, с. $420 ; 12$, с. 333 ; 13 , c. 215-216].

Познание смысла и роли классификации сделок на акты, сопряженные и не сопряженные с их восприятием, разумеется, предполагает, прежде всего, установление содержания понятия «восприятие волеизъявления» и его отграничение от смежных категорий.

Понятие, сущность и виды восприятия волеизъявления. Абсолютно очевидно, что анализируемая классификация не имеет никакого отношения к моменту непреложности изъявления воли вовне при совершении сделки (а в необходимых случаях - облечения волеизъявления в соответствующую форму), ибо подлинно «юридический смысл волеизъявлению, - как заявляет А.В. Томсинова, - придает именно ... опосредование воли вовне» $[14$, с. 79]. Собственно выражение субъектом воли и ее восприятие («распознание») другими лицами - «онтологически» автономные правовые феномены, что с неизбежностью ставит перед наукой вопрос об их сопряжении в рамках определенной юридической конструкции.

Восприятие, будучи субстанционально процессом приема и преобразования некоей информации (благодаря чему обеспечивается отражение волеизъявления), логично признается познавательным актом и в этом качестве противополагается волевым актам, связанным с формированием и выражением вовне воли. «Под восприятием, - рассуждает на сей счет Б.Б. Черепахин, - ...следует понимать доведение ... до сознания другого лица... Восприятие, как акт познавательный, существенно отличается от принятия, как акта волевого, волеизъявления» [12, с. 333]. Такого же мнения придерживаются В.В. Ванин [7, с. 61], Л.А. Новоселова [15, с. 173] и многие другие ученые.

Однако понятие «восприятие» в известном смысле в юриспруденции носит фигуральный характер. В целях обеспечения правовой определенности и недопущения злоупотреблений участниками оборота, во-первых, центр тяжести переносится с субъективного аспекта (реальное ознакомление с волеизъявлением, его «...доведение до сознания другого ли- 
ца...» [3, с. 57]) на объективные «индикаторы», когда о восприятии речь ведется с точки зрения отправления и доставки (а не, образно говоря, «прочтения») информационного сообщения (данная трансформация - заслуга германского законодательства, которое в начале XX в. «приравняло простую возможность ознакомления с ... сделками к самому ознакомлению с ними...» [11, с. 679]).

Во-вторых, восприятие в обозначенном контексте стало подразделяться на фактическое (если сообщение получено адресатом в действительности) и вмененное (в ситуации, когда адресат признается воспринявшим волеизъявление, в том числе и при его неполучении в действительности). Эта идея, правда, без «опоры» на анализируемую классификацию, получила отражение в предписаниях п. 1 ст. 165 ГК РФ, в силу которых юридически значимое сообщение считается доставленным и тогда, когда оно поступило лицу, которому было направлено, но по обстоятельствам, зависящим от него, не было ему вручено или адресат не ознакомился с ним. При таком достаточно сбалансированном подходе, с одной стороны, демонстрируется важное юридико-фактическое значение «коммуникации» (что актуально, помимо прочего, для адресата), с другой стороны, преодолеваются негативные последствия потенциального недобросовестного поведения адресата, к примеру, не желающего получать корреспонденцию (это правило, само собой, сориентировано на охрану интересов отправителя сообщения). Задача законодателя с позиции справедливого нормирования данного сегмента отношений - установление (абстрактно и/или конкретно) набора случаев, когда вмененное восприятие является недопустимым.

Как уже отмечалось, в приложении к сделкам, нуждающимся в восприятии, кардинальную роль играет момент ясного определения фигуры адресата. В этой связи интересной и дискуссионной оказывается проблема квалификации волеизъявления, адресованного неопределенному кругу лиц. Так, нетривиальной и сложной для интерпретации (что лишний раз свидетельствует о некоторой «хрупкости» концепта обособления нерецептивных актов в череде действий сделочного типа) является публичная оферта. Если рассмотрение «обычной» оферты как действия, требующего восприятия, практически бесспорно (поскольку она, напомним, связывает оферента лишь с момента получения ее адресатом - п. 2 ст. 435 ГК РФ), то аналогичная трактовка публичной оферты (для которой корневым является не собственно факт ее восприятия, а то обстоятельство, что оферент готов к заключению договора с любым, кто отзовется, - п. 2 ст. 437 ГК РФ), несколько уязвима. Пожалуй, с точки зрения более или менее четкого размежевания рецептивных и нерецептивных юридических актов (невзирая на 
все «но») волеизъявления, адресованные неопределенному кругу лиц (либо их существенная часть), должны восприниматься как нерецептивные. Здесь уместно упомянуть о том, что тезис о принципиальной возможности порождения правовых последствий не нуждающимися в восприятии сделками не только (более того, и не столько) для определенных субъектов, но и для неопределенного круга лиц признается сторонниками изучаемой градации (в частности, в круг волеизъявлений, не нуждающихся в приеме, Ю.С. Гамбаров включал «строго-односторонние сделки», которые обращены «к неопределенной массе публики» и не требуют уведомления о них какого бы то ни было определенного лица [1, с. 679]).

Ценность деления сделок на требующие и не требующие восприяmия: pro et contra. Надо сказать, что ценность разбираемой классификации сделок в науке далеко не априорна, причем ее «отрицание» производится по соображениям не только «утилитарного» свойства (необходимость восприятия превалирующего числа односторонних сделок, трудность выработки зримого разграничительного критерия и пр.), но и концептуального толка. Например, на концептуальном уровне ее обоснованность может быть опровергнута при характеристике сделки как представления заинтересованных лиц о чужом действии, его гражданско-правовой направленности и последствиях: один из ключевых постулатов означенной оценки, как небеспричинно указывает В.А. Белов, - правило восприятия, суть которого сводится к тому, что «ни одна сделка ... не может приобрести юридического эффекта ... прежде ее восприятия заинтересованным лицом... Представление о чужом действии никак не может сформироваться без его восприятия лицом иным, чем тем, кто его совершил; следовательно, такое восприятие абсолютно необходимо для того, чтобы действие могло считаться сделкой» (а потому даже «действия ... односторонние ... без акта их восприятия не могут быть сочтены односторонними сделками») [16, с. 627-628].

Разумеется, все волеизъявления, как убедительно заключал еще А. Манигк (ставя, кстати, под сомнение научную пригодность выделения сделок, не требующих восприятия), «должны давать возможность адресату распознать сделочную волю и отреагировать на нее, это является целью любого истинного волеизъявления» (к примеру, задается автор риторическим вопросом о том, «какие иные ... цели должно иметь завещание...?») $[17, \text { с. } 260]^{1}$.

${ }^{1}$ Любопытно, что А. Манигк замечал, что встречающееся в науке (Hellmann) paдикальное предложение об отделении не требующих восприятия волеизъявлений от категории волеизъявлений «с одной стороны ... необоснованно, с другой стороны, есть в этом разумное зерно...». 
Словом, трансляция воли («контакт с адресатом»), так или иначе, юридически небезразлична для всякого действия сделочного «калибра» (и в этом измерении словосочетание «сделка, не требующая восприятия» оказывается не совсем корректным). Тем не менее довольно ощутима и неидентичность влияния (причем не только и не столько степени, сколько характера) факта (не)восприятия на саму юридическую силу волеизъявления в зависимости от его попадания в ту или другую классификационную группу: для актов, не нуждающихся в «приемке», восприятие значимо, скорее, в ракурсе надлежащей реализации порождаемых волеизъявлением правовых возможностей, в то время как собственно возникновение и существование последних (в силу совершения волеизъявления - единственно или в комбинации с иными юридическими фактами) не детерминируется восприятием. Например, завещание, как верно указывал Б.Б. Черепахин (для верификации тезиса об отнесении завещания к сделкам, требующим восприятия), «устанавливает права на принятие наследства также в пользу наследников, не знающих о нем...», причем «наследник может даже принять открывшееся в его пользу наследство по завещанию, не зная о таковом...» [12, с. 333] (данная логика восходит к римскому частному праву, признававшему, что эффект преторского завещания как вида нерецептивной сделки «не зависит от того, ознакомлен наследник с волей наследодателя или нет» [2, с. 129]). Не менее нагляден казус с правомерным составлением завещания по поводу лишения наследства наследников по закону, когда распределение наследственной массы после смерти завещателя будет происходить без участия и учета интересов «лишенцев» (естественно, не считая случая, когда они имеют право на обязательную долю в наследстве) безотносительно к их осведомленности о составлении завещания и его содержании.

Изложенное, полагаем, не позволяет игнорировать фактор (не)обязательности восприятия волеизъявления при полновесной характеристике сделок и опосредует значимость разбираемой градации. При этом:

1) отнесение сделки к разряду требующих или не требующих восприятия существенно влияет на условия и момент наступления юридических эффектов ее совершения;

2) в свою очередь, трактовка сделки как рецептивной диктует необходимость установления (в централизованном или децентрализованном формате) и соблюдения правил, касающихся процедуры и адресата извещения о волеизъявлении (как правильно утверждает Я. Шапп, «при волеизъявлениях, нуждающихся в принятии, важную роль играет «горизонт 
адресата», в то время как при заявлениях, не требующих принятия ... данное обстоятельство не имеет значения» [13, с. 216]).

Весьма показательно, что затронутые аспекты оказываются в центре внимания авторов, констатирующих, что то или иное действие требует восприятия. Так, А.А. Новиков и А.И. Иванова, исходя из того, что воля на приватизацию жилого помещения «должна быть не просто ... объективирована вовне...», а требует и восприятия, заявляют, что волеизъявление «не может быть адресовано любому и каждому» (речь должна идти исключительно о должнике в возникающем обязательстве по передаче жилого помещения в собственность) $[18 ; 19]$. Ю.С. Харитонова, солидаризируясь с В.А. Рясенцевым в том, что акт одобрения совершенной неуполномоченным лицом сделки нуждается в восприятии, подчеркивает, что «адресатом одобрения ... должен быть контрагент по сделке, заключенной неуполномоченным лицом, а не любое лицо...» [20, с. 35].

Значение классификации не ограничивается приведенными моментами; среди прочего она, пожалуй, должна приниматься в расчет при толковании содержания (условий) сделки, о чем, в частности, справедливо заявляют С.Ю. Болонин («большинство односторонних сделок требуют восприятия волеизъявления», «при толковании таких сделок необходимо учитывать то, как воля лица, совершающего сделку, была воспринята лицом, которому она адресована» [6, с. 114]) и С.П. Жученко («практический смысл ... деления состоит в том, что требующие получения волеизъявления толкуются ... с учетом того, как ... волеизъявление могло быть понято контрагентом...», «при толковании же волеизъявлений, не требующих получения, анализу подлежит воля с учетом ее объективного отражения в волеизъявлении» [10, с. 377]).

Проблема выработки критерия разграничения сделок на требующие и не требующие восприятия. Одной из причин негативной критики деления, как указывалось, является отсутствие явного и общепризнанного различительного признака. В свое время на этом «печальном» обстоятельстве делал акцент А. Манигк, по словам которого, сохраняющим актуальность по сей день, «имеющиеся выводы ... недостаточны, чтобы предложить четкие принципы по поводу необходимости воспринимаемости волеизъявления. ...Их (волеизъявлений. - Ю. П.) качество как требующих и не требующих восприятия предстоит доказать, тем более что мы в отношении отдельных случаев не знаем, принадлежат ли они к первой или второй категории. Причина этого кроется ... в неопределенности наших представлений о требовании воспринимаемости, без которого прежняя наука вполне ... обходилась» [17, с. 258-259]. 
Очевидно, что разрешение поставленной проблемы подразумевает перво-наперво ответ на вопрос о том, какой юридический «функционал» таит в себе восприятие применительно к сделкам, нуждающимся в восприятии, в противовес иным сделкам, для которых «приемка» не выполняет соответствующих задач (а потому носит факультативный, а не императивный статус). Для описания указанной функциональной (не)зависимости (предопределенности), как правило, прибегают к следующим формулам:

a) о (не)наступлении правовых последствий сделки. По утверждению Б.Б. Черепахина, «к сделкам, не нуждающимся в восприятии, относятся ... сделки, которые порождают правовые последствия для определенных лиц или же для неопределенного круга лиц, независимо от их восприятия этими лицами» [12, с. 333]. По мнению Л.А. Новоселовой, «последствия ... сделок будут возникать: в первом случае - когда волеизъявление воспринято лицами, которым оно адресовано; во втором ...независимо от того, воспринято оно другими лицами или нет» [15, c. 173] (почти тождественные формулировки, касающиеся возникновения правовых последствий, мы находим у С.Ю. Болонина [6, с. 114]);

б) о (не)признании сделки совершенной (либо состоявшейся). Так, применительно к отказу представителя от полномочия Е.Л. Невзгодина полагает, что он «считается состоявшимся в момент доведения его до сведения представляемого...» $[21$, с. 70$]$;

в) о (не)вступлении сделки в юридическую силу. В частности, М.А. Егорова, трактуя односторонний отказ от исполнения договора в качестве сделки, требующей восприятия, указывает на то, что «отказ вступает в силу с момента доведения информации о нем контрагенту» [3, c. 57]. А.Д. Кожухова, попутно замечая, что в Германии исследуемое деление производится по моменту вступления сделки в силу, приходит к выводу о том, что «выделение сделок, требующих восприятия, имеет практическое значение: данные сделки вступают в силу с момента поступления волеизъявления адресату, а не с момента совершения данного волеизъявления» [11, с. 419-420] (то есть осязаемо противопоставляются «совершение» сделки и ее «вступление в силу»).

Сверх того, иногда авторы одновременно используют все или несколько из названных критериев. Так, в аргументации В.В. Ванина, при незнании контрагентом о существовании сделки, нуждающейся в восприятии, «последняя не вызывает юридических последствий и, следовательно, не имеет юридической силы» [7, с. 61]. С.С. Желонкин доказывает, что «если сделка ... не требует восприятия, то достаточно одного факта 
волеизъявления стороны, при котором сделка вступает в силу...», «сделка, требующая восприятия, производит правовые последствия ... в тот момент, когда она воспринята, не ранее этого», при этом «деление ... играет важную роль при ответе на вопрос о том, можно ли волеизьявление признать состоявшимся в каждой конкретной ситуации, а также с какого момента его можно признать состоявшимся» [4, с. 103-104]. По мнению А.А. Панова, «если придерживаться ... деления, то следует признать необходимость получения адресатом требующего восприятия волеизъявления, для того чтобы такое волеизъявление могло признаваться правом как волеизъявление в юридическом смысле и было способно породить правовые последствия. Поэтому деление ... играет важную роль при ответе на вопрос о том, можно ли волеизъявление признать состоявшимся...» [5, с. 66].

Понятно, что стержневое и базовое значение в плане внятного содержательного наполнения конструкций сделок, нуждающихся и не нуждающихся в восприятии, имеет уяснение соотношения (линий «взаимодействия») между понятиями (в том числе в темпоральном аспекте с позиции допустимости временного разрыва между явлениями, охватываемыми приводимыми далее категориями) в рамках как минимум следующих терминологических рядов:

a) «совершение сделки», «совершение волеизъявления» (при определенном видении выражение воли вовне эвентуально может не исчерпывать процесс совершения сделки);

б) «совершение сделки», «вступление сделки в силу», «создание сделкой прав и обязанностей» (тем более что российский законодатель активно употребляет названные термины, допуская несовпадение во времени подразумеваемых ими процессов: в соответствии с п. 1 ст. 157 ГК РФ при совершении сделки под отлагательным условием возникновение прав и обязанностей (в будущем!) ставится в зависимость от обстоятельства, относительно которого неизвестно, наступит оно или не наступит; на основании п. 1 ст. 957 ГК РФ договор страхования, если в нем не предусмотрено иное, вступает в силу в момент уплаты страховой премии или первого ее взноса, однако иное (скажем, в момент подписания соглашения) может быть предусмотрено договором; согласно ст. 1118 ГК РФ совершенное наследодателем завещание создает права и обязанности лишь после открытия наследства и т. д.).

Выдвинутая методологическая установка в том или ином виде о3вучивалась в доктрине. Например, Я. Шапп, настаивая на разведении феноменов выражения и вступления волеизъявления в силу, заключает, что «вопрос о том, в каком смысле волеизъявление действительно, следует 
отличать от вопроса о том, в какой момент оно приобретает юридическую силу» [13, с. 221].

«Глобально» оправданно выделить две принципиально возможные (и «непересекающиеся») модели отражения юридической роли восприятия в приложении к сделкам, нуждающимся в «приемке» (причем каждая имеет свои достоинства и недостатки):

1) концепт, в соответствии с которым восприятие выступает элементом (этапом) совершения акта (сообразно чему до восприятия адресатом сделка не просто не влечет правовые последствия и т. п., а вообще считается несовершенной (несуществующей)); простота и логичность данной модели делает ее довольно привлекательной;

2) конструкт, предполагающий разведение собственно совершения сделки и ее восприятия, и тогда восприятие, к которому будет приурочиваться вступление сделки в силу и т. д., лежит за пределами совершения акта (в некотором смысле данная вариация, по-видимому, близка немецкому гражданскому законодательству, по результатам изучения которого А.В. Томсинова указывает, что «волеизъявление, требующее вручения, считается сделанным с того момента, как субъект изъявил свою волю, но вступление его в силу зависит от участия другой стороны» [14, с. 80]).

Вопрос об «алгоритме» оценки сделки как (не)рецептивной. При постулировании обоснованности изучаемой «сортировки» сделок необходимым становится закрепление механизма установления принадлежности той или иной сделки к определенному классу. В науке, отечественной и зарубежной, разумно подчеркивается, что соответствующая квалификация может базироваться на указаниях закона, а также проистекать из существа юридического действия. В частности, А.А. Панов, заключая, что «большинство волеизъявлений требуют восприятия», отмечает, что «это может следовать из закона либо из существа волеизъявления» [5, с. 66]; «необходимость принятия адресатом, - полагает Я. Шапп, - вытекает либо из природы сделок, либо из закона» [13, с. 215].

Подход одновременного принятия в расчет воли законодателя и сущностных особенностей сделки по факту уже работает в российской правовой системе. Как известно, порою закон непосредственно закрепляет необходимость отправления (получения) соответствующего извещения и/или «привязывает» наступление определенных правовых последствий к моменту такого отправления (получения). Скажем, в силу п. 1 ст. 450.1 ГК РФ при реализации лицом права на односторонний отказ от договора (исполнения договора) с момента получения контрагентом соответст- 
вующего уведомления договор прекращается (если иное не оговорено правовыми актами либо договором).

Иногда же, напротив, разбираемый коммуникативный аспект не попадает в орбиту внимания законодателя в рамках специального нормирования. Так, при регламентации отношений по поводу прекращения обязательства зачетом ГК РФ ограничивается ремаркой о том, что для зачета достаточно заявления одной стороны (ст. 410). Вместе с тем и в подобного рода ситуациях обязательность оповещения не ставится под сомнение. В частности, в приведенном случае с зачетом ясно, что для аннулирования обязательственно-правовой связи заявление о зачете должно быть доставлено стороне либо считаться доставленным по правилам ст. 165.1 ГК Р $\Phi^{1}$.

Сочетание обоих факторов (недвусмысленная позиция законодателя и «естество» сделки), думается, в целом достойно обеспечивает гибкое и эффективное решение поставленной проблемы, поскольку:

а) непосредственное законодательное регулирование трансляционного компонента исключает правовую неопределенность при оценке акта как (не)рецептивного (что особенно актуально в дискуссионных случаях, например, относительно согласия третьего лица на совершение сделки), а равно может быть полезным для нюансирования отдельных моментов (адресат, сроки доставки и т. д.);

б) дополнительный учет существа сделки преодолевает возможную пробельность законодательства (тем более что по большому счету, как небезосновательно подчеркивал Gottschack, «требование воспринимаемости волеизъявления не может быть предписано законом, но всегда следует из «порядка и природы вещей» $[17$, с. 260]).

Кроме того, обстоятельного обсуждения заслуживает вопрос о закреплении общего презумптивного правила. Отталкиваясь от тезиса о типичности совершения сделок, нуждающихся в восприятии (причем по причинам объективного свойства, ибо наступление частноправовых эффектов для лиц, к которым обращено волеизъявление, все-таки предполагает владение ими информацией о совершении такого волеизъявления), предпочтительным, наверное, является вариант интерпретации («по умолчанию») сделки как рецептивного действия (иное, однако, может следовать из закона или существа сделки).

${ }^{1}$ О некоторых вопросах применения положений Гражданского кодекса Российской Федерации о прекращении обязательств : постановление Пленума Верховного Суда РФ от 11 июня 2020 г. № 6 // Российская газета. 2020. № 136. 
Сфера приложения классификации волеизъявлений на требующие и не требующие восприятия. Общеупотребительным является применение конструкции рецептивных и нерецептивных действий в отношении односторонних сделок. Так, Б.Б. Черепахин указывает, что именно «односторонние сделки могут быть нуждающимися и ненуждающимися в восприятии другими лицами» [12, с. 333]. Данная мысль воспроизводится и многими другими правоведами (о том, что «односторонние сделки могут являться нуждающимися в восприятии другими лицами и не требующими такого восприятия», говорит С.Ю. Болонин [6, с. 114]; на односторонние сделки экстраполирует дифференциацию по факту воспринятости (рецептивности) на требующие и не требующие восприятия волеизъявления А.Д. Кожухова [11, с. 418-422]).

Конечно, момент (не)обязательности установления факта восприятия волеизъявления адресатом играет особую роль главным образом в ситуации совершения односторонних сделок. Сказанное, однако, не означает исключительности распространения (в той или иной мере) деления только на названные юридические акты (стандартность подобной «сцепки» не означает ее строгой безусловности) и порочности его приспособления к некоторым иным действиям. Рецептивный аспект, полагаем, может иметь важное правовое значение и при совершении:

a) односторонних волеизъявлений, сделочная квалификация которых ущербна или остается полемичной (например, акта голосования участника гражданско-правового сообщества);

б) договоров, правовые эффекты которых изначально обращены не только к лицам, являющимся их участниками (договора в пользу третьего лица, договора финансовой аренды, соглашения об уступке права требования, корпоративного договора и др.).

Так, из норм ст. 430 ГК РФ не следует обусловленность приобретения третьим лицом права требовать исполнения обязательства из договора, заключенного в пользу третьего лица, ни согласием последнего, ни даже его ознакомлением с соглашением (другое дело, что третье лицо, естественно, может отказаться от права, предоставленного ему по договору).

Наоборот, в свете того, что лизингополучатель (даже не будучи субъектом договора купли-продажи имущества, передаваемого в аренду) правомочен предъявлять требования напрямую продавцу (что знаменует вторжение, хотя и легитимное, в область интересов последнего), ГК РФ рационально исходит из необходимости уведомления лизингодателем продавца при приобретении у него имущества о том, что оно предназначено для передачи в аренду определенному лицу (ст. 667). Это, конечно, 
вовсе не означает, что в отношениях между арендодателем и арендатором лизинговый договор является сделкой, требующей восприятия по указанным мотивам, но юриспруденция должна грамотно объяснить основания (причины) возникновения связанности лизингополучателя и оповещенного должным образом продавца имущества, чему, думается, может продуктивно поспособствовать адаптация анализируемой дифференциации сделок к подобного рода соглашениям (научный потенциал классификации - шире традиционно понимаемого), при этом системного раскрытия (не только в привязке к договору финансовой аренды) требует вопрос о видовом разнообразии последствий (не)восприятия договорных волеизъявлений (в том числе в сопоставлении с эффектами рецепции односторонних сделок).

\section{Библиографический список}

1. Гамбаров Ю.С. Курс гражданского права. Т. 1. Часть общая. СПб. : Тип. М.М. Стасюлевича, 1911. $791 \mathrm{c.}$

2. Дождев Д.В. Римское частное право : учебник для вузов. М. : ИНФРА-М - НОРМА, 1997. 704 с.

3. Егорова М.А. Особенности одностороннего отказа от исполнения договора как односторонней сделки // Законы России: опыт, анализ, практика. 2007. № 8. С. 55-59.

4. Желонкин С.С. Сделки, требующие восприятия в контексте Постановления Пленума Верховного Суда РФ от 23 июня 2015 года № 25 // Юридическая мысль. 2016. № 2 (94). С. 102-105.

5. Панов А.А. К вопросу о категориях воли, волеизъявления и порока воли в теории юридической сделки // Вестник гражданского права. 2011. № 1. С. 52-81.

6. Болонин С.Ю. Особенности правотолкования при автономном индивидуально-правовом регулировании // Актуальные проблемы экономики и права. 2010. № 2. С. 112-116.

7. Ванин В.В. Правовая природа извещения о проведении торгов на заключение государственного (муниципального) контракта // Пробелы в российском законодательстве. 2012. № 5. С. 59-62.

8. Егоров А.В. Структура обязательственного отношения: наработки германской доктрины и их применимость в России // Вестник гражданского права. 2011. № 3. С. 241-274.

9. Невзгодина Е.Л. Прекращение представительства без реализации полномочия // Вестник Омск. ун-та. Сер.: Право. 2009. № 1 (18). С. $29-34$. 
10. Жученко С.П. Толкование договора // Практика применения общих положений об обязательствах : сб. ст. / отв. ред. М.А. Рожкова. М. : Статут, 2011. С. 371-400.

11. Кожухова А.Д. К вопросу о классификации односторонних сделок по факту воспринятости // Вопросы науки и образования: теоретические и практические аспекты : матер. Междунар. (заочной) науч.-практ. конф. / под общ. ред. А.И. Вострецова. Нефтекамск : Науч.-издат. центр «Мир науки», 2017. С. 418-422.

12. Черепахин Б.Б. Правопреемство по советскому гражданскому праву // Черепахин Б.Б. Труды по гражданскому праву. М. : Статут, 2001. C. $307-442$.

13. Шапп Я. Система германского гражданского права : учебник. М. : Междунар. отношения, 2006. 360 с.

14. Томсинова А.В. Понятие «Willenserklärung» (волеизъявление) в Германском гражданском уложении 1900 г. // Вестник Московск. ун-та. Сер.: Право. 2012. № 5. С. 69-83.

15. Новоселова Л.А. Согласие должника на уступку требования // Сделки: проблемы теории и практики : сб. ст. / отв. ред. М.А. Рожкова. М. : Статут, 2008. С. 165-179.

16. Белов В.А. Гражданское право. Т. II. Общая часть. Лица, блага, факты : учебник для бакалавров. М. : Юрайт, 2012. 1093 с.

17. Манигк А. Развитие и критика учения о волеизъявлении // Вестник гражданского права. 2008. № 2. С. 231-260.

18. Новиков А.А., Иванова А.И. Правопреемство mortis causa при приватизации жилых помещений в судебной практике // Закон. 2013. № 1. C. 89-102.

19. Новиков А.А., Иванова А.И. Правопреемство mortis causa при приватизации жилых помещений в судебной практике // Закон. 2013. № 2. С. $129-145$.

20. Харитонова Ю.С. Заключение сделки неуполномоченным лицом: изменения в ГК РФ и судебная практика // Право и экономика. 2013. № 11. С. 32-37.

21. Невзгодина Е.Л. Прекращение полномочия без реализации: гражданско-правовой аспект // Вестник Пермск. ун-та. Сер.: Юридические науки. 2008. Вып. 1 (1). С. 70-72. 
POVAROV Iurii Sergeevich

Candidate of Sciences (Law), Associate professor of the Department of Civil and Business Law, Samara National Research University named after academician S.P. Korolev, Samara, Russia.

E-mail:sl-su@mail.ru

\section{DISTINCTION BETWEEN TRANSACTIONS REQUIRING AND NOT REQUIRING PERCEPTION: GROUNDS AND SIGNIFICANCE}

The proposed scientific grouping of transactions into those requiring and not requiring perception has not been systematically reflected in Russian civil legislation; moreover, the scientific potential of this classification is often questioned. Purpose: to explain the nature and significance of the distinction between transactions requiring and not requiring perception; to analyze the approaches used to establish the criterion for such a distinction; to develop a mechanism for determining whether a transaction belongs to a particular classification group; and to study the permissibility of extrapolation of division into other (rather than unilateral transactions) legal acts. Methods: the author uses general theoretical methods of formal and dialectical logic, as well as specific scientific methods such as legal-dogmatic, legal modeling, comparative legal, interpretation of legal norms. Results: the author proves the irrelevance of ignoring a factor of (not) compulsory perception of will and, as a consequence, the significance of the studied gradation (while the classification of a transaction as requiring or not requiring perception affects the conditions and timing of its legal effects, and the interpretation of the transaction as receptive is necessary to establish and comply with the rules on the procedure and the addressee of the notification of will). The author highlights the main models for reflecting the legal role of perception in the application to transactions that need perception; the author assesses positively the approach to identifying a transaction as (non) receptive based on the direct instructions of the law and the essence of the transaction; the idea of the advisability of adapting the division also to legal acts that are not unilateral transactions is carried out.

Keywords: transaction; expression of will; making a transaction; perception of the transaction; legal force; message delivery; addressee of the message.

\section{References}

1. Gambarov Yu.S. Kurs grazhdanskogo prava. Tom 1. CHast' obshchaya [Civil law course. Volume 1. General part]. St. Petersburg, Printing house M.M. Stasyulevich Publ., 1911. 791 p. 
2. Dozhdev D.V. Rimskoe chastnoe pravo [Roman private law]. Moscow, INFRA-M - NORMA Publ., 1997. 704 p.

3. Egorova M.A. Peculiarities of a single-handed effort of fulfilling a contract as a single-handed transaction. Zakony Rossii: opyt, analiz, praktika = Laws of Russia: Experience, Analysis, Practice, 2007, no. 8, pp. 55-59. (In Russian).

4. Zhelonkin S.S. Transaction requiring the perception in the context of the Plenum of the Supreme Court on 23 June 2015 № 25. YUridicheskaya mysl' $=$ Legal Thought, 2016, no. 2 (94), pp. 102-105. (In Russian).

5. Panov A.A. On the question of the categories of will, expression of will and vice of will in the theory of legal transaction. Vestnik grazhdanskogo prava $=$ Civil Law Review, 2011, no. 1, pp. 52-81. (In Russian).

6. Bolonin S.Yu. Peculiarities of law interpretation in autonomous individual-legal regulation. Aktual'nye problemy ekonomiki i prava = Actual Problems of Economics and Law, 2010, no. 2, pp. 112-116. (In Russian).

7. Vanin V.V. The legal nature of the notice on tendering on the conclusion of the state (municipal) contract. Probely $v$ rossijskom zakonodatel'stve $=$ Gaps in Russian Legislation, 2012, no. 5, pp. 59-62. (In Russian).

8. Egorov A.V. The structure of the contractual relationship: developments of the German doctrine and their applicability in Russia. Vestnik grazhdanskogo prava $=$ Civil Law Review, 2011, no. 3, pp. 241-274. (In Russian).

9. Nevzgodina E.L. Termination of representation without exercising powers. Vestnik Omskogo universiteta. Seriya: Pravo = Herald of Omsk University. Series: Law, 2009, no. 1 (18), pp. 29-34. (In Russian).

10. Zhuchenko S.P. Interpretation of the contract. In Rozhkova M.A. (ed.). Praktika primeneniya obshchih polozhenij ob obyazatel'stvah. Sbornik statej [Practice of applying general provisions on obligations. Collection of articles]. Moscow, Statut Publ., 2011, pp. 371-400. (In Russian).

11. Kozhukhova A.D. On the issue of classification of unilateral transactions based on the fact of perception. In Vostretsov A.I. (ed.). Voprosy nauki $i$ obrazovaniya: teoreticheskie $i$ prakticheskie aspekty. Materialy mezhdunarodnoj (zaochnoj) nauchno-prakticheskoj konferencii [Science and education issues: theoretical and practical aspects. Materials of the international (correspondence) scientific and practical conference]. Neftekamsk, Mir nauki Publ., 2017, pp. 418-422. (In Russian).

12. Cherepakhin B.B. Succession under Soviet civil law. In Cherepakhin B.B. Trudy po grazhdanskomu pravu [Works on civil law]. Moscow, Statut Publ., 2001, pp. 307-442. (In Russian). 
13. Shapp J. Sistema germanskogo grazhdanskogo prava [System of German civil law]. Moscow, International relations Publ., 2006. 360 p.

14. Tomsinova A.V. The concept of «Willenserklärung» (expression of will) in the German Civil Code of 1900. Vestnik Moskovskogo universiteta. Seriya: Pravo = Bulletin of Moscow University. Series: Law, 2012, no. 5, pp. 69-83. (In Russian).

15. Novoselova L.A. The debtor's consent to the assignment of the claim. In Rozhkova M.A. (ed.). Sdelki: problemy teorii i praktiki. Sbornik statej [Transactions: problems of theory and practice. Collection of articles]. Moscow, Statut Publ., 2008, pp. 165-179. (In Russian).

16. Belov V.A. Grazhdanskoe pravo. Tom II. Obshchaya chast'. Lica, blaga, fakty [Civil law. Volume II. General part. Persons, benefits, facts]. Moscow, Yurayt Publ., 2012. 1093 p.

17. Manigk A. Development and criticism of the doctrine of expression of will. Vestnik grazhdanskogo prava = Civil Law Review, 2008, no. 2, pp. 231-260. (In Russian).

18. Novikov A.A., Ivanova A.I. Succession mortis causa in the privatization of residential premises in judicial practice. Zakon $=$ Law, 2013, no. 1, pp. 89-102. (In Russian).

19. Novikov A.A., Ivanova A.I. Succession mortis causa in the privatization of residential premises in judicial practice. Zakon $=$ Law, 2013, no. 2, pp. 129-145. (In Russian).

20. Kharitonova Yu.S. Conclusion of a transaction by an unauthorized person: changes in the Civil Code of the Russian Federation and judicial practice. Pravo $i$ ekonomika = Law and Economics, 2013, no. 11, pp. 32-37. (In Russian).

21. Nevzgodina E.L. Termination of powers without implementation: civil legal aspect. Vestnik Permskogo universiteta. Seriya: YUridicheskie nauki = Perm University Herald. Series: Juridical Sciences, 2008, iss. 1 (1), pp. 70-72. (In Russian). 